\title{
Enhancing Pharmacy Practice with Technology: A Utopian Dream?
}

\author{
Jason Howorko
}

I mproving medication safety, enhancing the efficiency of health care, and increasing pharmacy's professional scope of practice are just a few of the benefits of implementing technology. In fact, some of the technologies available today would allow pharmacy practice to move forward by leaps and bounds. Yet many Canadian hospitals continue to miss the mark when it comes to the adoption of these technologies and systems.

The idea of unit-dose drug distribution was conceptualized as early as the 1960s, but today, 50 years later, many Canadian institutions have not yet adopted this basic distribution practice. According to the Hospital Pharmacy in Canada 2007/2008 Report (www.lillyhospitalsurvey.ca/hpc2/content/2008_report/ 2007_08_full.pdf), only 49\% of respondents to the main survey (chapter D) and 62\% of respondents to the CSHP 2015 baseline survey (chapter J) reported using unit-dose distribution systems for at least $90 \%$ of the beds in their hospitals.

No wonder bedside point-of-care technologies, including bar-coding, automated medication dispensing cabinets, electronic medication records, computerized prescriber order entry, clinical decision support tools, and shared community and hospital medication records, still appear to be decades away. For example, as noted in the Hospital Pharmacy in Canada 2007/2008 Report (chapter J), only 7\% of hospitals have computerized prescriber order entry systems in place and only $1 \%$ have bar-coded medication verification at the bedside.

If these technologies have so many benefits, why has their adoption proceeded so slowly in Canada? Do the various stakeholders not realize the importance of using technology to improve the health care system and enhance patient safety? Or are the costs simply too great? Will high litigation payments form the catalyst that forces health care officials and governments to take note of this issue? Or is continued advocacy required?

CSHP is a strong advocate for the adoption of technology in hospitals and related health care settings. A few notable examples:

- CSHP participated in the development of and provided endorsement for the Canadian Pharmaceutical Bar Coding Project: Joint Technical Statement on Pharmaceutical Automated Identification and Product Database Requirements (published in 2010 by the Institute for Safe Medication Practices Canada and the Canadian Patient Safety Institute; see www.ismp-canada.org/ barcoding/download/ Can PharmBarcode_ Joint TechnicalStatement.pdf).

- The CSHP 2015 initiative has an entire goal

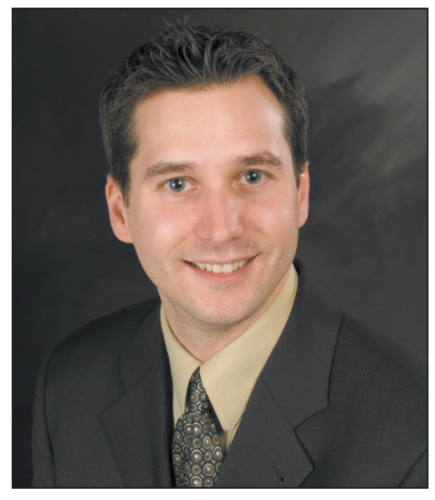
focused on the application of technology to improve the safety of medication use (Goal 5) (see www.cshp.ca/dms/dmsView/2_CSHP-2015Goals-and-Objectives-Feb-25\%2707-w-Appdx-revMay\%2708.pdf).

- CSHP successfully advocated for improvements to the Licensed Natural Health Products Database so that clinical decision-support tools could continue to include natural health products.

- CSHP conducted an advocacy campaign on the implementation of unit-dose medication distribution systems to enhance patient safety.

- CSHP has representatives on the National e-Pharmacy Task Force and the Blueprint for Pharmacy Steering Committee.

- CSHP participated in the development of and endorsed the implementation plan of the Blueprint for Pharmacy (see www.pharmacists.ca/content/about_cpha/whats_happening/ cpha_in_action/pdf/BlueprintImplementationPlan.pdf), which includes deliverables related to information and communication technology.

The time for action is now! As a profession, we need to ensure that technology as a critical safety tool moves to the forefront. Otherwise, we may be waiting another 50 years before it becomes a reality.

Jason Howorko, BSP, BSC, ACPR, is Past President and External Liaison for the CSHP. 